\title{
LOS REPUBLICANOS ESPAÑOLES Y LOS OTROS. IMPACTO E INFLUENCIA DE LOS MODELOS REPUBLICANOS FORÁNEOS, 1840-1874 ${ }^{1}$ \\ Spanish Republicans and the Others. Impact and Influence of Foreign Republican Models, 1840-1874
}

\author{
FLORENCIA PEYROU \\ Universidad Autónoma de Madrid \\ florencia.peyrou@uam.es
}

Cómo citar/Citation

Peyrou, F. (2017).

Los republicanos españoles y los otros. Impacto e influencia de los modelos republicanos foráneos, 1840-1874. Revista de Estudios Políticos, 175, 331-356. doi: http://dx.doi.org/10.18042/cepc/rep.175.11

\section{Resumen}

La referencia a repúblicas o democracias de todo tipo y de todos los tiempos fue una constante en la cultura política republicana de la España decimonónica. En el caso de los modelos del pasado constituían en algunas ocasiones un factor legitimador como precedente histórico de gran longevidad, coronado frecuentemente por éxitos económicos y militares, y en otras, una manera de reconocer y distanciarse de los errores del pasado. En el caso de las alusiones a modelos vigentes en la época, eran la demostración de la viabilidad, de la posibilidad de la democracia y la república, y del progreso y desarrollo en todos los terrenos que estas formas de Estado y de gobierno traían consigo inevitablemente. Muchas veces, además, la alusión a repúblicas del pasado o a las existentes en ese preciso momento era una manera de hacer política nacional en tiempos de represión política, sobre todo durante el período isabelino. El presente texto está dedicado a analizar la manera en que, durante las décadas centrales del siglo $\mathrm{xIX}$, los republicanos españoles

Este artículo ha sido realizado en el marco del proyecto HAR2012-32713 del Plan Nacional de I+D+i. 
gestionaron la historia y la memoria democrático-republicana, y los modelos de repúblicas foráneos.

\title{
Palabras clave
}

Republicanismo; república; España; historia; memoria.

\begin{abstract}
Nineteenth century Spanish republicans constantly referred to democracies and republics of all kinds and all periods. Historical models were usually used as legitimizing factors, as they provided long-standing and successful precedents - above all in military and economic terms. They also served to allow recognition and avoidance of errors from the past. References to existing $19^{\text {th }}$ century republics served to demonstrate the viability of democracy and republicanism, and the progress and development that these forms of State and government inevitably encouraged. Occasionally, reference to existing or past republics was a means of doing national politics in times of political repression, above all during the reign of Isabella II. This article is devoted to analyzing the way $19^{\text {th }}$ century Spanish republicans managed democratic/republican history and memory, including regarding foreign republican models.
\end{abstract}

\section{Keywords}

Republicanism; Republic; Spain; History; Memory. 


\section{SUMARIO}

I. REPÚBLICAS HISTÓRICAS Y MODELOS DE REFERENCIA. II. EPÍLOGO: DE LOS MODELOS DE REFERENCIA A LOS PROYECTOS DE ESTADO. BIBLIOGRAFIA.

En 1856, el demócrata español Roque Barcia reconocía con amargura que «España odia(ba) a los estranjeros». A su juicio, ese odio procedía de dos instintos: del instinto nacional que se rebelaba contra las pretensiones usurpadoras a las que habían tenido que hacer frente en numerosas ocasiones, y del instinto "del monopolio del sistema» que rechazaba las propuestas reformistas que se elaboraban allende las fronteras. Ese odio había llegado «a ser tan nuestro como nuestra sangre» y constituía la base de la intolerancia civil y religiosa, y de la "parálisis» que había sumido al país en la postración. Sin embargo, ese odio no era esencia de la españolidad, sino fruto del sistema político, económico y social que dominaba en España. Y Barcia comentaba con audacia que, si en Suiza rigiera "una institución cuyo resorte capital consis(tiera) en la fascinación del lujo, del boato, del esplendor», si allí existiera "la enseñanza perpetua de una corte que no es grande sino porque es ceremoniosa y fingida», si las propiedades estuvieran amortizadas, se pusieran trabas a la producción, se recaudaran impuestos monstruosos, en definitiva, si se implantara en Suiza "nuestra política, nuestra moral, nuestra administración», los suizos estarían también sumidos en la vileza y la abyección (Barcia, 1856: 127-129).

Los republicanos españoles, por el contrario, miraban al exterior y proponían reformas y medidas ya practicadas en otros lares «con resultados materiales y morales magníficos» (Orense, 1862: 18). Sobre todo, se fijaban en repúblicas o democracias de todo tipo y de todos los tiempos. La referencia a los modelos del pasado permitía legitimar sus aspiraciones y estrategias, ya que las experiencias pretéritas eran vistas como precedentes coronados por éxitos económicos y militares. En el caso de las alusiones a modelos vigentes durante el lapso estudiado, eran la demostración de la viabilidad, de la posibilidad de la democracia y la república, y del progreso y desarrollo en todos los terrenos que estas formas de Estado y de gobierno traían consigo inevitablemente. En ocasiones, además, la alusión a repúblicas del pasado o a las existentes en ese preciso momento era una forma de hacer política nacional en tiempos de represión, sobre todo durante el período isabelino. El presente texto está dedicado a analizar la manera en que, durante las décadas centrales del siglo XIX, 
los republicanos españoles gestionaron la historia y la memoria democrático-republicana, y los modelos de repúblicas foráneos.

\section{REPÚBLICAS HISTÓRICAS Y MODELOS DE REFERENCIA}

Los primeros republicanos españoles aparecieron en la esfera pública alrededor de 1840. En su mayoría eran liberales avanzados descontentos con el principio posrevolucionario de la soberanía compartida entre la corona y las Cortes instituido en 1837 y con los proyectos reactivos que los gobiernos moderados diseñaron hasta 1840 , que terminaron rechazando el sistema de la monarquía constitucional y defendiendo que la única solución posible para garantizar la libertad era la supresión del trono. Tras la caída de Espartero, la política represiva que llevó a cabo el moderantismo en el poder y el carácter restringido del régimen que se instauró entonces fue aumentando, de manera gradual y desigual, el contingente de individuos radicalizados que se fueron persuadiendo de la imposibilidad de que la monarquía constituyera el escenario real de una verdadera libertad individual y ejercicio de la soberanía nacional (Peyrou, 2008a y 2008b). El distanciamiento de la corona estuvo además determinado por varias cuestiones. En primer lugar, por la promulgación de la Constitución de 1845, que reforzó enormemente los poderes de la corona; en segundo lugar, por la práctica parlamentaria que se desarrolló durante el reinado de Isabel II, que privilegió el poder ejecutivo en detrimento del legislativo y abusó de disoluciones y reales decretos; por último, por la incapacidad de la corona de situarse por encima de los partidos políticos constituyendo un verdadero poder moderador y su asimilación progresiva al partido moderado (Marcuello, 1986; Burdiel, 2004). Posteriormente, la experiencia del Bienio terminó de demostrar a muchos demócratas la imposibilidad de combinar trono y libertad. De hecho, A. Borrego se referiría al «giro» que, desde 1856, había "tomado la democracia española como partido republicano" (Borrego, 1885: 2). Este proceso, debido a la represión del momento, resulta muy difícil de rastrear, pero parece evidente si tenemos en cuenta el Manifiesto publicado en 1858 por la Junta Nacional del Partido Democrático Español, que proclamaba como forma política del Estado la República, o el hecho de que en 1868 el Partido Democrático se transformara en Partido Demócrata Republicano Federal ${ }^{2}$.

«Manifiesto político de la Junta Nacional del Partido Democrático Español», Madrid, 1 de febrero de 1858. PRO FO 72, 936, Howden a Malmesbury, 1-5-1858. 
La mayoría de estos sectores consideró durante mucho tiempo que mientras se garantizara la libertad y la soberanía nacional la cuestión de la forma de gobierno no era especialmente relevante. Así, no teorizaron tanto sobre la república como sobre la necesidad de someter a la monarquía a la voluntad de la nación (García Rovira, 1998). La democracia, en definitiva, era lo más importante, incluso para aquellos que se declaraban partidarios de la caída del trono. Democracia, en líneas generales, significaba sufragio «universal» o muy extendido, predominio del poder legislativo, descentralización administrativa y un conjunto de libertades civiles, políticas, sociales y económicas. Por ello, un modelo muy bien valorado por los demócratas españoles fue el británico, conocido por algunos de ellos tras distintos períodos de exilio en Inglaterra durante los años 1820 y 1830.

Un ejemplo en este sentido es José María Orense, que estuvo establecido en Londres desde 1823 hasta aproximadamente 1832. Allí observó el sistema representativo y los movimientos políticos que tuvieron lugar durante ese período, particularmente la campaña a favor de la libertad de los católicos, que se inició en 1823 de la mano del irlandés O'Connell y concluyó con la emancipación de los mismos en 1829. A su vuelta a España, Orense se mostró inicialmente partidario del modelo de monarquía constitucional británica en la que la Corona, los Lores y los Comunes estaban perfectamente equilibrados en el Parlamento. De hecho, en 1844 abogó por el establecimiento de un senado hereditario y nombrado por el rey y se declaró admirador de la «escuela inglesa", que debía servir de paradigma en el terreno constitucional ${ }^{3}$. En 1858 seguía pensando que para establecer un régimen democrático bastaba con imitar «todo lo bueno» del «método inglés»; pero ahora se refería únicamente a la garantía de los derechos individuales, y criticaba la existencia de dos Cámaras legislativas y el derecho a veto de la corona. Cinco años más tarde, Orense explicaba que «la monarquía verdaderamente constitucional», tal y como se practicaba en Inglaterra desde 1688 y a la que él había aspirado en un principio, consistía en una «transacción entre el gobierno popular o republicano [...] y la monarquía pura» que requería «mucha buena fe en su cumplimiento" para que no se convirtiera en una farsa (Orense, 1863: 7). Pero esto era precisamente lo que había ocurrido en España, y lo que había ido empujándolo hacia el republicanismo. El marqués se fue convenciendo de que la buena marcha de la monarquía constitucional dependía de «las buenas o malas intenciones del monarca» y de que era inherente a los reyes el «rodearse de los enemigos de los ciudadanos» (Orense, 1870: 4). A partir de ahí, empezó a defender con más ahínco los modelos de los Estados Unidos de América y

3 Diario de Sesiones de Cortes, 20-11-1844, p. 541. 
Suiza. Sin embargo, en ningún momento antepuso la forma de Estado al régimen político en general, por lo que aquella nunca fue para él el factor determinante a la hora de valorar los modelos foráneos. A la vez que se declaraba republicano, Orense reconocía que la libertad era una verdad en Inglaterra, Estados Unidos, Suiza, Bélgica, Piamonte, Portugal y Brasil, y una farsa en Francia, Austria, Prusia, España «y la docena de las Repúblicas Hispano-Americanas» (Orense, 1862: 22).

Por el mismo motivo, el modelo inglés nunca fue desechado. La Discusión señalaba en 1857 que los dos únicos países que habían alcanzado la libertad eran Inglaterra y Estados Unidos ${ }^{4}$, mientras que Fernando Garrido, tres años más tarde, expresaba el buen concepto que tenía del Reino Unido, sobre todo por la garantía de las libertades y derechos individuales y su prosperidad económica. A su juicio, las instituciones inglesas debían ser contempladas «si no como un modelo perfecto y digno de imitación en todas sus partes, al menos como una prueba de comparación».

La cámara popular es uno de los poderes principales de aquel país. Verdad es que la corona y la cámara de los Lores participan con el parlamento, del poder soberano, pero su participación es harto secundaria. La mayoría de la cámara popular, y no la de la cámara aristocrática, es quien decide, quien da el triunfo o la derrota a los ministerios; y la influencia del parlamento es tan grande, tan irresistible su autoridad, que nadie duda en Inglaterra que una ley discutida y aprobada por él, aunque tuviera por objeto abolir los privilegios de la aristocracia, o transformar la forma de gobierno del país, no encontraría resistencia (Garrido, 1860: 21 y 23).

Este predominio de la democracia convertía la gestión de la memoria y la historia de las repúblicas del pasado en un asunto complejo, porque por lo general estaban bastante lejos de adecuarse a las maneras en que, en las décadas centrales del siglo XIX, los demócratas y republicanos españoles comprendían ese concepto. Por ello, si bien estos últimos se declararon en todo momento herederos de la Revolución de 1789, «madre de las Cortes del año 12», y principio inaugural del movimiento europeo hacia la democracia, la República de 1793, y posteriormente la de 1848, fueron generalmente rechazadas 5 . Los republicanos, por tanto, valoraron de forma unánime la

4 La Discusión, 1-3-1857. Pi y Margall también escribía por esas fechas que pedía lo que existía en Estados Unidos e Inglaterra. La Discusión, 15-7-1858.

5 La Asociación, 2-9-1856. También Ordax Avecilla señalaba la Revolución francesa impulsora de la regeneración de España: la «exorbitante masa de ideas que la 
dimensión revolucionaria universal y los principios de 1789, pero no los modelos concretos de organización política que surgieron de esos acontecimientos (Castro, 1990: 149).

La Primera República estaba manchada por la experiencia del Terror. En un artículo anónimo que se publicó en El Huracán en 1841 se afirmaba que «nosotros no pretendemos imitar a la comisión de salvación pública ni a los girondinos, que no les hemos estudiado para modelos, que no les reconocemos ni a unos ni a otros como jueces únicos competentes e inapelables de los principios bajo que han de girar las revoluciones modernas» ${ }^{6}$. En 1856, el periódico La Asociación disculpaba «en cierto modo los sucesos del 93" por considerarlos «hijos de circunstancias fatales y en estremos estraordinarias», pero rechazaba absolutamente su reproducción en «ningún pueblo de Europa», y añadía que «son cuando menos necios los que piensan en los sucesos del 93 para hacer que marche la causa de la libertad y se afiance». Y Pi y Margal añadía que "la democracia misma del 93 no fue la nuestra»: si aquella estaba basada en la existencia de «un poder fuerte y de un Estado» que absorbían «por completo al individuo» y en «el orgullo de las castas vencedoras», lo que denominaba "democracia moderna» se fundaba sobre "la autonomía de la voluntad humana, es decir, sobre un principio eminentemente racional, sobre la igualdad, sobre la justicia» ${ }^{7}$.

También se rechazaba el modelo de una república una e indivisible, ya que era un obstáculo para la igualdad. Orense explicaba que la centralización del poder, adoptada por la Convención para «adquirir fuerzas y poder lidiar con la Europa coaligada», había sido "buena como medida transitoria», pero era "una calamidad como medida permanente». "Con la centralización», sentenciaba, «una nación se convierte en esclava de los dominadores de la capital» (Orense, 1862: 57). Castelar, por su parte, afirmaría más tarde que «una República centralizada, en que la administración de la capital y la dirección del gobierno se exageren y se extremen, caerá en manos de una oligarquía de burócratas» (Castelar, 1874: 354). La centralización fue también uno de los principales factores de rechazo de la II República francesa, aunque no el único.

La revolución de febrero tuvo un impacto notable en muchos republicanos españoles. Es conocido el testimonio de Castelar:

Revolución francesa puso en circulación y el rechazo a la conquista napoleónica, hicieron que España se encontrase a sí misma, a partir de las Cortes y Constitución de Cádiz» (Avecilla, 1843: V-VI).

6 El Huracán, 18-11-1841.

7 La Asociación, 2-9-1856. F. Pi y Margall, «¿Cuál ha sido la conducta política de la democracia? ¿Cuál debía ser?», La Razón, 1-4-1856. 
Tenía 17 años. La revolución de 1848, aquel hermoso canto de libertad, que había despertado a tantos pueblos dormidos, que había sonreído a tantas almas apagadas, resonó en mi corazón con tan deleitosísima armonía, que inclinado por educación y por sentimiento a ideas religiosas [...] me apasioné de la Democracia, creyendo siempre ver en ella la realización del Evangelio. La Libertad, la Igualdad, la Fraternidad, ¿no son reflejo de la trinidad divina en el alma? (Castelar, 1856: IV).

Sixto Cámara, por su parte, afirmaba que 1848 había influido «poderosamente en el movimiento político de los pueblos y en las composiciones y recomposiciones de la opinión» (Cámara, 1848: V). Sin embargo, el desarrollo de los acontecimientos no fue valorado de la misma manera. Para Orense, el modelo francés de 1848 había dejado «un gran ejército, un enorme presupuesto, una centralización que ahogaba al país y solo se tomó de los Estados Unidos lo de la presidencia, que confiada a cualquiera, hubiera sido un gran disparate, confiada a Napoleón, fue de parte del pueblo un suicidio» (Orense, 1862: 78). Más tarde, el mismo autor pidió a sus correligionarios que «escarment[aran] con la desgracia de Francia y evit[aran] en cuanto sea dable, cuando t[uvieran] la República, que tras la presidencia pud[iera] volver la monarquía». El poder central debía tener «por principal objeto conservar la unidad nacional. El gobierno de los pueblos deb[ía] residir en los Estados» (Orense, 1870: 5). También desde el periódico La Discusión se señaló que «lo hecho en 1848» se había reducido a "llamar república lo que antes se llamaba monarquía» ${ }^{8}$.

Los franceses no servían tampoco como modelo de referencia en lo que se refiere a las estrategias. Para Orense, se caracterizaban por «hacer primero las cosas y pensarlas después». Y añadía que alemanes e ingleses constituían en este extremo un mejor ejemplo a seguir, explicando «hasta la saciedad su sistema para que todos sepan cuál es. Es el camino más largo, pero más seguro» (Orense, 1862: 16). Y Emilio Castelar señalaba, en una línea similar, que el problema de Francia eran sus «cambios bruscos del absolutismo a la anarquía y de la anarquía al absolutismo", sus "excesos de libertades reprimidos por excesos de dictaduras», las «tendencias a la igualdad» que daban lugar a «oligarquías burocráticas» y la combinación de "proclamación de principios humanitarios con procedimientos de terror, de guerra, de matanza» (Castelar, 1874: 22). Por otro lado, Orense también afirmaba que las dos repúblicas francesas sí constituían una buena muestra de que los republicanos sabían rectificar, de que buscaban «sólo el bien» y eran capaces de eliminar conductas y

8 La Discusión, 13-11-1860. 
estrategias perniciosas: en 1793, se había abusado en Francia del cadalso político, «y su primer cuidado en 1848, sin exigirlo nadie de los otros partidos, fue abolir la pena de muerte en materias políticas». Mazzini fue aún más radical en Roma, un año más tarde: «la abolió enteramente» (Orense, 1862: 19).

Francia constituyó, en definitiva, una referencia compleja. Si bien los modelos republicanos ensayados allí eran rechazados, fue un referente constante para los demócratas y republicanos españoles, que se vieron muy influidos por sus "moldes organizativos", sus principios cardinales (libertad, igualdad, fraternidad), su simbología (gorros frigios, banderas tricolores, himnos) e imágenes y en ocasiones ideario ${ }^{9}$. Por lo demás, el rechazo de lo francés derivaba también de una intensa xenofobia y del hecho de que constituía el principal modelo de referencia para el liberalismo moderado (Elorza, 1997: 114118). Hubo que esperar hasta el establecimiento de la III República en Francia para que esta se convirtiera en modelo de referencia para un sector del republicanismo español, aunque la centralización continuó siendo unánimemente condenada. Si Salmerón la valoraba como «una república mesurada, prudente, pero enérgica» (De Diego, 2008: 236), fue sobre todo defendida por Castelar. Establecida gracias a un «mutuo acuerdo» entre monárquicos que «abandonaron sus ideas de monarquía» y republicanos que «abandonaron sus principios impracticables», el régimen francés finisecular se caracterizaba por «el gobierno sin arbitrariedades, el orden sin marasmo, la libertad sin motines, la democracia sin exageraciones, la República sin utopías, la estabilidad sin reacción y el progreso sin sacudimiento» ${ }^{10}$. En cualquier caso, el «referente primordial en el imaginario republicano» durante la Restauración siguió siendo, como en épocas anteriores, más la Revolución de 1789 que «la coetánea Tercera República» (De Diego, 2008: 231).

Otra memoria complicada de gestionar fue la de las repúblicas clásicas y medievales. Dada la primacía que para los republicanos decimonónicos tenían los derechos y libertades individuales, parecía muy difícil evitar la conclusión de que «jamás fueron democracias», como afirmó José González Menéndez en 1841; algo que reiteraría veinte años más tarde Vicente Martínez Muller: «fueron repúblicas aristocráticas basadas en el privilegio» ${ }^{11}$. Orense, por su parte, señalaba la existencia en ellas de esclavos que «hacían todos los trabajos», y afirmaba que los individuos estaban sacrificados al Estado

9 La influencia de la simbología francesa en el republicanismo español, en Orobon (2005).

10 El Globo, 29-8-1878.

11 El Huracán, 10-2-1841. V. Martínez Muller, «El horizonte y la democracia», La Discusión, 19-4-1860. 
(Orense, 1862: 78). Sin embargo, constituía un precedente muy apetecido como para desecharlo sin más, por la legitimidad histórica que podía aportar a los proyectos republicanos y para evitar las acusaciones de improvisación y novedad. De hecho, había gran empeño en insistir en que la república no era nueva:

[...] no ha dejado de estar en práctica en el mundo, al menos desde Solón acá. Hoy en Grecia, al otro día en Italia, esotro en Flandes, el de más allá en la Germania, y hasta en un rincón de la misma Rusia, luego en Suiza, en Noruega y otros puntos, siempre ha vivido, más o menos esplendente, más o menos pura (García Ruiz, 1861: 32).

Por ello se realizaron algunos esfuerzos por vincular a las repúblicas antiguas con la concepción moderna de la democracia. Eugenio García Ruiz fue uno de los publicistas que más se explayaron en este extremo, aunque ello implicara dar cabida a algunos anacronismos. Pero es que a García Ruiz no le interesaba especialmente describir con exactitud los modelos de Atenas, Roma, Florencia o Génova, sino que a partir de estos precedentes históricos podía cumplir un doble objetivo: deslegitimar a la fracción socialista del movimiento democrático —en un momento de intensas polémicas_- y difundir los principios del partido en un momento de libertades restringidas. Era, pues, una manera de hacer política interna y de difundir el programa republicano-democrático, especialmente las libertades individuales y los derechos políticos. Así, el autor señalaba que «de Atenas, de la legislación de Solón han partido y parten todos los pensadores que quieren la democracia, es decir, la libertad y la igualdad dentro del Estado", mientras que "de Esparta, de la legislación de Licurgo, han partido y parten todas las escuelas socialistas, comunistas y reaccionarias, que quieren que el Estado absorba el individuo por completo» (García Ruiz, 1861: 13).

A su juicio, Solón había instaurado la libertad individual, la libertad del trabajo, el derecho de propiedad, el derecho de asociación y la libertad de enseñanza. Además:

El poder soberano le depositó en la asamblea de Atenas y de toda la nación ática, y todo ciudadano tenía derecho de asistir a ella y votar; decidiendo así el más pobre como el más rico, el más sabio como el más ignorante, sobre todas las leyes, sobre la paz y la guerra, sobre los impuestos y sobre los grandes y pequeños intereses sociales (García Ruiz, 1861: 21).

El credo democrático, que aprovechaba para enumerar (y que se podía resumir en «autonomía del individuo lo mismo que derechos inherentes a la 
naturaleza del hombre, inagenables e ilegislables»), había sido, en definitiva, «reconocido y casi completamente practicado por Solón». Y desde entonces nunca había dejado de estar en práctica en algún punto: en Tebas, Rodas, Roma, las repúblicas italianas (que «llegaron a ser en los siglos medios tres potencias formidables» o en las ciudades libres alemanas, particularmente en Lübeck, Bremen y Hamburgo, que «merced a su gobierno democrático [...] se convirtieron en centros de comercio y de industria tan florecientes en el norte como lo eran en el sur Florencia, Pisa y Génova». Y sentenciaba, "con vida pública, con ciudadanos, con democracia en una palabra todo progresa» (García Ruiz, 1861: 35, 36, 61, 71).

García Ruiz aludía también a los Concejos Soberanos de Flandes, a la ciudad de Novgorod durante los siglos XIII al XV, donde «la soberanía residía en la universalidad de los ciudadanos», y a Suiza. Allí, desde el siglo xIV, no había dejado de reinar la libertad; allí, «merced al espíritu democrático, que predomina en la confederación», existía una «industria floreciente y una agricultura sin disputa la más perfeccionada de Europa» (García Ruiz, 1861: 89). $\mathrm{El}$ autor explicaba el funcionamiento de la confederación y el régimen específico de cada uno de sus cantones. Su conclusión era contundente:

La democracia domina en general en este país hace ya más de 550 años: merced a ella, el pueblo que le habita es sencillo, trabajador, industrioso, inteligente y el de mejores costumbres de Europa, de la cual se ha hecho respetar, sin embargo de no contar con más de dos millones y medio de habitantes. Una cosa notable nos ofrece hoy este venturoso país, y es que, sin embargo de existir la más completa libertad de conciencia, no se altera por esto la admirable armonía que preside a todas las aspiraciones sociales. Todos los suizos son patriotas, todos los suizos son libres, todos los suizos se consideran como hermanos (García Ruiz, 1861: 102).

Sin embargo, Suiza no fue una referencia muy extendida en la publicística democrático-republicana, tal vez porque, como señaló el propio García Ruiz y reiteró posteriormente Ceferino Tresserra, los gobiernos internos de la Confederación eran muy desiguales, cada uno de ellos gozaba de libertades distintas y «algunos carec[ía]n de las más principales como la de cultos, imprenta, comercio, etc.» (Tresserra, 1870: 3).

El modelo más influyente —y admirado- para los demo-republicanos españoles fue indiscutiblemente el de los Estados Unidos de América. Ya en 1835, el mariscal de campo Pedro Méndez Vigo, uno de los primeros liberales españoles que manifestó abiertamente su republicanismo, señalaba que el gobierno republicano nunca había sido «mejor entendido y aplicado que en los Estados Unidos de América», «república feliz» basada en los siguientes 
principios: sufragio universal, juicio por jurados, separación del gobierno y las leyes de las cuestiones religiosas. Vigo explicaba que, en los primeros años de existencia de esta república, «se batieron en la imprenta, en las juntas populares, en la tribuna, dos partidos que eran el federalista, o aristocrático, y el democrático. A la entrada de Jefferson a la presidencia, el segundo dominó y desde entonces ha ido desapareciendo el primero, hasta el punto de que en el día ninguno osa hacer profesión de él». Como consecuencia, no había un pueblo «en que los derechos del ciudadano fuesen más respetados, en que los individuos tuviesen más participación en el gobierno, en que las masas estuviesen más perfectamente niveladas en todos los goces sociales» (Méndez Vigo, 1835: 87, 130, 133).

Poco después, en 1841, era el cura párroco de Baños de Béjar, José González Menéndez, quien manifestaba su admiración por los «Estados angloamericanos» porque formaban «una poderosa confederación puramente democrática»: «allí no ecsiste aristocracia de nacimiento, de clase ni de elección, ni aún esa que se quiere titular de talento: la de riqueza menos aún puede ecsistir porque allí la riqueza produce comodidad y goces a su poseedor, pero no poder, ni político ni social». Menéndez no dejaba de señalar el punto negro de la esclavitud, pero también dejaba claro su rechazo en aras de un régimen de verdadera igualdad. Tampoco ocultaba su admiración por la prosperidad que reinaba en los Estados Unidos:

Los caminos de hierro, los canales, la navegación de vapor en ninguna nación ni aún en la inglesa se hallan tan generalizados y perfeccionados los capitales superabundan, el bienestar material, la cultura e instrucción del pueblo no admite cotejo con otro alguno, y por último allí no existe la mendicidad y el extranjero que acaba de arribar con disposiciones para el trabajo está seguro de encontrar al momento una existencia ${ }^{12}$.

En definitiva, para él «la república federada anglo-americana» era la «más semejante a las instituciones que destinamos a la península» ${ }^{13}$. Menéndez afirmaba conocer este modelo político gracias a la lectura de Tocqueville, de Chevalier, de Murat y de la «mayor parte de los modernos viajeros que han ecsaminado y descrito el estado de aquellas poderosas y felices repúblicas» ${ }^{14}$. La obra de Tocqueville fue crucial. Publicada en Francia en 1835, se editó una primera traducción en España ya en 1843 (Imp. D. N. Sánchez), seguida de

12 El Huracán, 11-2-1841.

13 El Huracán, 12-2-1841.

14 El Huracán, 11-2-1841. 
nuevas ediciones en 1854 (Imp. J. Trujillo) y 1855 (Imp. I. Cumplido). Posteriormente fueron muy importantes también las traducciones de Edouard Laboulaye, Emile Jonveaux y J. A. Spencer, entre otros (Capellán, 2011). Los lectores españoles contaron además con relatos y descripciones de viajes realizadas por ilustres compatriotas. Ramón de la Sagra, por ejemplo, recorrió los Estados Unidos de abril a septiembre de 1835, y publicó sus impresiones en París un año más tarde (Sagra, 1836). También el demócrata cubano Antonio Angulo Heredia pasó una temporada en el mencionado país y relató lo que allí vio en unos Estudios sobre los Estados Unidos de América y el Self Government, que se publicaron en Madrid en 1865 y fueron previamente unas lecciones impartidas en el Ateneo.

Si bien Ramón de la Sagra dejaba claro en la introducción de su libro que, pese al entusiasmo con que hablaba de las instituciones de la federación, su intención no era presentarla como «modelo de imitación a la desgraciada España» (sobre todo porque consideraba que el pueblo español estaba muy mal dispuesto para digerir «los sazonados frutos del árbol frondoso y robusto que vegeta[ba] en el privilegiado suelo de los Estados Unidos»), los republicanos y demócratas que escribieron posteriormente sí lo hicieron. Es preciso señalar, por lo demás, que Sagra no hacía ninguna mención a la política, sino que se centraba en caminos y canales, acueductos, barcos de vapor, manufacturas, cárceles, hospitales y hospicios, educación, comercio, navegación, rentas, milicia, bancos, pesos y medidas, topografía y cultivos (Sagra, 1836: XII).

Eugenio García Ruiz señalaba en la obra ya mencionada que «aparte del borrón de la esclavitud, la democracia ha reinado en los Estados Unidos». Y a la democracia se debía el que el pueblo norteamericano hubiera aumentado su población desde 1787, de cuatro millones de habitantes a los cerca de cuarenta millones que había a la altura de 1860 . También a la «verdadera libertad» se debía su marina inmensa, su industria floreciente, su comercio extenso y sus fabulosas riquezas. García Ruiz destacaba la elección de los representantes por sufragio de todos los ciudadanos mayores de 25 años, mientras que el Senado era elegido por la autoridad legislativa de cada Estado. El presidente tenía veto una sola vez, y no era más que el jefe del ejército y la armada. Su cargo duraba cuatro años. Subrayaba también la existencia del jurado y la ausencia de títulos de nobleza, así como la garantía de los derechos individuales ilegislables. Por último, alababa el sistema penitenciario, que mitigaba los castigos y trataba de llevar a los criminales por el camino de la virtud (García Ruiz, 1861: 107-111).

Fernando Garrido, por las mismas fechas, también celebraba la libertad que reinaba en los Estados Unidos, causa a su vez de su impresionante prosperidad. Garrido señalaba el aumento de población, el aumento de la marina mercante, su nivel de ilustración, su «superávit presupuestario», el modesto 
salario del presidente y el reducido número de su ejército. Pero lo más importante eran las instituciones políticas:

[...] son las más libres que se hayan practicado por ahora, en nación alguna. Los derechos individuales están garantizados por la ley y por la costumbre. La libertad de imprenta es verdadera libertad, puesto que no tiene traba legal que se oponga a su ejercicio. [...] el derecho de reunión, sin armas o con ellas, no tiene límites; y respecto al de asociación, baste decir que las hay fundadas con el objeto ostensible de disolver la confederación de los Estados que componen la república. Todos los cargos públicos son de elección popular, y como el jurado aplica las leyes, la opinión pública es, en todos los casos, el verdadero soberano del país. La religión, completamente independiente del Estado, es un acto de conciencia y no un deber social, lo que produce la sinceridad en los actos relijiosos y la moralidad de los sacerdotes de todos los cultos, porque, dependiendo su subsistencia de la voluntad de los feligreses y no del gobierno que para nada interviene en tales asuntos, tienen que ser por fuerza modelos de probidad y virtud, si quieren que el sacerdocio les produzca para vivir. Cuarenta y tantas religiones distintas se practican simultáneamente en los Estados Unidos (Garrido, 1860: 37).

Garrido mencionaba también el punto negro de la esclavitud, pero confiaba en que desaparecería en un corto plazo. Que dos republicanos de tendencias tan distintas (socialista y federal uno, individualista y unitario el otro) coincidieran en su valoración de este modelo constituye una muestra más de la fundamental unidad que caracterizaba a la cultura política republicana de las décadas centrales del siglo XIX (Peyrou, 2009). Los sectores individualistas rechazaron toda relación con el socialismo para alejar de las filas republicanas el fantasma del desorden y la anarquía y por identificarlo con la «absorción del individuo por el Estado». Sin embargo, ninguno de los que se identificaron con la reforma social defendieron este extremo y se limitaron a defender —como hizo el propio Garrido— «el principio de asociación» para la producción y/o el consumo. Todos defendían, por lo demás, «la autonomía o soberanía individual, y como resultado de esta, la soberanía nacional, declarando que el hombre tiene derechos propios naturales que la sociedad y las leyes deben respetar y garantizar» (Garrido, 1860: 1294). Una soberanía individual que no se hallaba mejor garantizada que en los Estados Unidos. Por otro lado, las referencias a este modelo nunca fueron demasiado extensas, no se tendió a hacer estudios en profundidad y las alusiones se caracterizaban más bien por su carácter superficial. Esto, unido a que los demócratas y republicanos españoles entendieron y defendieron - hasta el Sexenio- el federalismo de acuerdo con la lectura que del mismo realizara Tocqueville (como 
descentralización administrativa y centralización gubernativa), contribuyó también a la general aceptación del modelo (Peyrou, 2010).

Solo Antonio Angulo realizó un análisis más detallado del funcionamiento institucional de los Estados Unidos, y en particular de su régimen federal. En sus Estudios sobre los Estados Unidos de América empezaba subrayando que Europa tenía «mucho que aprender, sobre todo en el orden político, de la gran república americana», y añadía que esta última debía ser «el modelo práctico e histórico que tengan siempre a la vista los que deseen sinceramente contribuir con sus esfuerzos a la inevitable aunque lenta evolución de nuestra patria por el camino del progreso». A la vez, reconocía también la dificultad de este objetivo, teniendo en cuenta que, a diferencia de la norteamericana, "la democracia europea» tenía que "destruir pacífica o violentamente los restos de injustas instituciones de otros tiempos». Angulo destacaba la garantía de los derechos y libertades individuales que reinaba en los Estados Unidos, pero a su juicio, los dos puntos clave del sistema norteamericano eran la democracia y el self-government. En cuanto a lo primero, Angulo destacaba el sufragio «universal» masculino y el hecho de que no hubiera «cuerpo ni individuo alguno» a quien se confiara por completo el poder supremo. El pueblo «nunca se desprend[ía] de todos sus derechos para transferirlos a las manos de sus delegados». El pueblo, sentenciaba, se gobernaba «a sí mismo por medio de delegados con poder limitado» (Angulo, 1865: 14 y 69-70).

En lo que respecta a lo segundo, se refería al sistema federal. Su obra destaca por ser la comprensión más acertada del complejo mecanismo institucional introducido por la Constitución de 1787. Si hasta entonces los demócratas y republicanos españoles habían definido el federalismo como una «descentralización» que consistía en que el municipio y la provincia (aunque fueran denominados «estados federales») tuvieran independencia en cuanto a sus «intereses locales y provinciales», según Garrido, o a sus «gobiernos interiores, económicos y administrativos», de acuerdo con Romualdo Lafuente, ahora se detallaban más las competencias que tenía, de acuerdo con la Constitución de 1787, cada estado federal (Peyrou, 2010: 268).

Angulo explicaba que el ayuntamiento constituía «por sí solo un Estado libre e independiente, perfectamente organizado" (1865: 62). Legislaba sobre contribuciones municipales y ejecutaba «sus propias resoluciones sin intervención ni sanción ninguna del llamado gobierno general», y añadía:

El carácter intrínseco de los Estados Unidos es el de una agregación nacional; es una nación compuesta de una tríada nunca conocida ni realizada hasta entonces en la historia y formada por los estados particulares, todo el pueblo y los Estados Unidos. [...] El pueblo, es decir, la reunión de muchas unidades individuales soberanas, aceptó la constitución que dio nacimiento a los Estados Unidos. 
Ciertos derechos no concedidos y tan soberanos en su naturaleza como los renunciados a favor del gobierno de la Unión, quedaron radicando en el pueblo de cada estado. Estos derechos de los estados particulares consagran y preservan el derecho soberano del pueblo [...]. El Congreso puede legislar únicamente sobre objetos distintamente definidos en la Constitución, pero no sobre aquellos, con mucho más numerosos e importantes, que el pueblo de cada Estado particular ha reservado a su resolución propia. El congreso no puede nunca intervenir en los derechos especiales de los Estados y de las distintas localidades, ni posee omnipotencia parlamentaria [...]. Ningún Estado particular es jefe ni cabeza, sino que todos se hallan unidos en virtud de derechos y prerrogativas iguales en principio. Ni el Congreso ni el presidente, aún en nombre de la Unión, se hallan revestidos de poderes y derechos que disminuyan o pongan en peligro los de cada Estado. Así el presidente, al paso que ejerce el supremo poder ejecutivo en nombre de la totalidad del pueblo, no tiene influencia oficial ninguna sobre el poder ejecutivo de cada uno de los Estados. Tampoco tiene el Congreso derecho alguno para legislar sobre los asuntos internos de los Estados particulares, y de esta manera la descentralización de los poderes garantiza la general independencia. El presidente es el funcionario por cuyo medio entran las naciones extranjeras en tratos oficiales con los Estados Unidos, pues cada Estado particular ha cedido en favor de la Unión su derecho especial a tratar con el extranjero. Excepto los casos enumerados en la Constitución fundamental, y relativos a los derechos concedidos a la Unión, el poder central ejercido en nombre de todo el pueblo por el presidente y el Congreso no puede pesar jamás sobre las porciones especiales del pueblo que constituyen cada estado distinto. Así, la individualidad del Estado conserva sus derechos de una manera tan sagrada como cada miembro particular de la comunidad (Angulo, 1865: 75-77).

Era la primera vez que se mostraba una comprensión más precisa del modelo federal norteamericano, basado, como es bien sabido, en la atribución de competencias al gobierno federal por parte del poder constituyente (el pueblo de los diferentes estados), que conservaba el conjunto de poderes no transferido, y en un reparto de competencias entre dos niveles de poder que tenían la autoridad última sobre las mismas, sin que se produjera ningún tipo de ordenamiento jerárquico. Este modelo derivaba de una noción de soberanía desdoblada proveniente de Althusius que no tuvo impacto por lo general en el constitucionalismo europeo (ni en los republicanos decimonónicos), donde dominaba la nación de soberanía absoluta e indivisible de Bodino y Hobbes (Chopin, 2002; Fleiner-Gerster, 1993).

Esta mejor comprensión del modelo federal de los Estados Unidos pudo contribuir en la atribución de competencias políticas a las distintas unidades territoriales en que debía dividirse España, algo en que la mayoría de los 
republicanos coincidía ya a la altura del Sexenio, aunque esto es indudablemente resultado de un proceso más complejo que no cabe relatar en este artículo. Solo convendría señalar que, pese a todo, hasta 1874 ningún republicano defendió un reparto de competencias entre las distintas entidades soberanas en pie de igualdad. En todos los proyectos se vislumbra una jerarquía en la que la preeminencia última correspondía al gobierno nacional. Los poderes municipales-provinciales no tenían competencias sobre el "pueblo" de su demarcación, sino que operaban sobre cuestiones administrativas del territorio. Solo había un pueblo español, cuyas leyes políticas debían ser elaboradas por la Asamblea Nacional (Peyrou, 2010: 276).

A partir de 1868, el modelo norteamericano se convirtió en una referencia omnipresente en las Cortes y los debates constitucionales, valorado por todos los grupos revolucionarios que defendían los derechos individuales, y especialmente por la minoría republicana que apreciaba además ausencia de monarquía. $\mathrm{El}$ «pro-norteamericanismo político» continuó durante la Restauración entre los republicanos federales y los krauso-institucionistas. Si para los primeros los Estados Unidos conformaban un ejemplo de «democracia federal donde la unidad de la nación se presentaba en perfecta armonía con la autonomía del individuo, del municipio y la provincia», para los segundos era un modelo a imitar de «sistema democrático constitucional» (Capellán, 2011: 64, 67) ${ }^{15}$.

En cuanto a las repúblicas latinoamericanas, durante muchos años estuvo fuera de duda que no constituían ningún modelo a seguir debido a «la inestabilidad del poder ${ }^{16}$. Pedro Méndez Vigo celebró en la obra ya mencionada que las independencias de estos países se hubieran llevado a cabo sobre las bases de la soberanía popular y el derecho de los pueblos a gobernarse por sí mismos, de que los partidarios del derecho divino no hubieran podido oponerse al entusiasmo revolucionario, y que los nuevos Estados no estuvieran bajo la influencia de las viejas monarquías europeas. Pero los Estados hispanoamericanos eran presa de continuas facciones. El problema, a su juicio, derivaba de la gran diferencia de intereses que reinaba entre las distintas clases que componían la «sociedad hispano-americana». La población se había unido para lograr la independencia, y una vez «conseguido el grande objeto, entraron en combate aquellos mismos intereses». Combate individual entre los aspirantes a unos mismos destinos y combate de principios entre los que pre-

15 Pi y Margall manifestó su admiración por la República de los Estados Unidos («tu eres la democracia [...]; tu fuiste la primera en escribir los sagrados e imprescriptibles derechos del hombre») en A la República de los Estados Unidos de América, publicada en 1896 (Pi y Margall, 1998).

El Huracán, 10-2-1841. 
tendían mantener la herencia colonial y los que pedían cambios consiguientes a la nueva estación política del país. Los principios de privilegio e igualdad, intolerancia y libertad, entraron entonces en colisión. «En las constituciones de algunos estados y en sus leyes orgánicas se quiso contentar a muchos», con la consecuencia de "la desmoralización de todas las clases» (Méndez Vigo, 1835: 45, 80, 81). Esta visión se mantuvo durante muchos años. En 1854, por ejemplo, se reiteraba que "en casi todos los estados de América» reinaban desórdenes. Eran «teatro de las ambiciones de muchos que se disputa[ban] el mando" y no había allí "constituciones verdaderamente democráticas» ${ }^{17}$. Esta visión solo fue modificada por Castelar.

En 1874 explicaba la complejidad de los procesos que habían tenido lugar en América del sur. Las transformaciones súbitas, decía, eran muy difíciles:

[...] no bastaba con adquirir la independencia para adquirir un gobierno ordenado, ni con proclamar la República para tener una educada democracia [...]. La inexperiencia de aquellos pueblos recién nacidos a la vida pública, las dificultades de las innovaciones recién planteadas en la sociedad, que es de suyo conservadora; la secular educación colonial, las consecuencias naturales de una guerra en que habían de brotar todos los inconvenientes de la dictadura y del caudillaje; cuanto dependía de circunstancias ajenas, completamente ajenas a las instituciones, fue atribuido por nuestra ciega reacción al influjo letal de la República (Castelar, 1874: 8).

Sin embargo, consideraba que el período revolucionario, marcado por las guerras civiles, la anarquía y las dictaduras, ya había concluido. Se había pasado ahora a un período de estabilización y organización. La estabilización pasaba por dos caminos: que los poderes supremos nacieran de las leyes, y no de las revoluciones; y que la presidencia legalmente constituida, terminara su mandato también de manera legal y en el plazo correspondiente. Esta «maravillosa transformación» había tenido ya lugar en América:

El antiguo pueblo colonial, educado como nosotros en largo absolutismo; salido apenas de la servidumbre; lanzando de la tremenda guerra por la independencia a las terribles guerras civiles; de los estremecimientos epilépticos de la anarquía al reposo letal de la dictadura; mezclado con razas que parecen inaccesibles a nuestra cultura [...]; ha adquirido por sí mismo el sentido político necesario para fundar en la ley sus poderes (Castelar, 1874: 11).

17 El Tribuno, 13-9-1854. 
Castelar comentaba la situación de algunas de estas repúblicas: en Chile el poder era estable y el gobierno, amovible; Argentina tenía una Constitución semejante a la suiza: «dos presidentes han llenado con sus nombres un lustro»; «el general Mitre concluyó pacíficamente su presidencia, depuso el poder cuando lo exigió la ley. El doctor Sarmiento le ha sucedido en el mando, y le ha sucedido por el voto solemne regular del pueblo». En México, Juárez rendía un "culto religioso» a la legalidad: «él ha restaurado la patria y la República [...]. Pero su mérito mayor ha consistido en conservar el gobierno legal contra todas las facciones y todos los facciosos». Pero el ejemplo más digno, para Castelar, era el de Perú. Tras la muerte del coronel Balta, todo indicaba el advenimiento de una dictadura militar. El pueblo de Lima y Callao se armó para defender sus derechos y «la dictadura pasó rápida, fugaz como un delirio. El pueblo peruano volvió por sus leyes, volvió por su soberanía, volvió por su derecho». El nombramiento del doctor Pardo significaba, a su juicio, que habían pasado en América "las revoluciones anárquicas, las dictaduras sangrientas, el régimen vulgar del sable». Y concluía: «El Nuevo Mundo ha venido a la vida para realizar en toda su pureza la democracia moderna. [...] La amovilidad del poder y su responsabilidad, la separación entre la Iglesia y el Estado, la enseñanza laica, la federación de los pueblos, han hallado en el nuevo continente sólidas bases para erigirse con verdadero rigor y verdadera estabilidad». En definitiva, América había «establecido en el mundo moderno los dos principios esenciales a la vida: la democracia, y el organismo de esta vida, la República» (Castelar, 1874: 13-14).

\section{EPÍLOGO: DE LOS MODELOS DE REFERENCIA A LOS PROYECTOS DE ESTADO}

Los republicanos y demócratas españoles insistieron en la necesidad de establecer en España el sufragio «universal», pero también otorgaron una importancia fundamental a la garantía de un conjunto de derechos y libertades civiles, políticas, económicas y sociales, y a algunas otras medidas e instituciones como la descentralización, la milicia nacional o el jurado. Desde este punto de vista, se apoyaron abundantemente en ejemplos extranjeros, que no tenían por qué ser exactamente repúblicas o democracias, para legitimar el modelo de Estado que pretendían edificar. Orense, en este sentido, no dejó de señalar su objetivo de aplicar las reformas que habían producido buenos resultados ya en Francia, Inglaterra, Estados Unidos, Bélgica, Holanda o Suiza, entre otros países. Y explicitaba que el sufragio universal funcionaba en los Estados Unidos, mientras que "Inglaterra con sus reformas marcha hacia él». También había funcionado en Francia en 1848 y 1849, y la presencia en la 
Asamblea de legitimistas y la elección de Luis Napoleón demostraban que las elecciones habían sido «una verdad». Había libertad de imprenta y seguridad individual garantizada por el habeas corpus en Estados Unidos, Inglaterra, Bélgica y Suiza. En los tres primeros países reinaba el derecho de reunión pacífica y de asociación, y además había Milicia Nacional, descentralización provincial y municipal, y los alcaldes eran nombrados por los pueblos, mientras que en Suiza se habían abolido las aduanas.

Había juicios por jurados en Estados Unidos e Inglaterra en materia civil y criminal, y en Francia en materia criminal. En Inglaterra y Estados Unidos, además, reinaba la libertad de enseñanza y de establecimiento de bancos, y en ambos países se habían abolido las quintas, las matrículas del mar, los pasaportes, las loterías, los estancos de la sal y del tabaco, los derechos de puertas y los derechos de consumo (en este último punto precisaba que en Inglaterra se venían disminuyendo desde hacía varios años y la tendencia era a extinguirlos). En varios estados austríacos existía enseñanza primaria gratuita, Toscana había establecido la contribución única, directa y general, en Silesia se habían realizado reformas de las leyes hipotecarias para crear bancos territoriales, y en Francia se habían reformado los aranceles en sentido liberal. La contribución progresiva se había establecido en Baviera y era la idea dominante de los reformadores ingleses y franceses. Todas estas reformas, concluía Orense, formaban el verdadero sistema liberal y constituían la base del modelo estatal que se pretendía erigir en España (Orense, 1851, 1862).

Al mismo tiempo, como se ha señalado, los demócratas y republicanos españoles no dejaron de tener un modelo de referencia ineludible, y este modelo fue el de los Estados Unidos de América. Este modelo no funcionó solo como medio de difusión o legitimación de las reformas defendidas por estos sectores. Tuvo verdaderas consecuencias en el horizonte de futuro que contribuyeron a diseñar, ya que dio lugar a proyectos de organización política y territorial nacional y transnacional inspirados en el mismo. En primer lugar, se reclamaba la formación de unos Estados Unidos Ibéricos tras la unión de España y Portugal. Fernando Garrido, en este sentido, propuso en La Regeneración de España una federación integrada por 18 estados (Castilla la Nueva, Castilla la Vieja, Vascongadas, Aragón, Navarra, Cataluña, Baleares, Asturias, Galicia, Extremadura, Tras os Montes, Beira, Alentejo, Sevilla, Valencia, Andalucía, Murcia y Canarias). Señalaba también que «los vascos y catalanes que ocupan las dos vertientes de los Pirineos, y que desde hace poco más de cien años están divididos en dos naciones distintas, se unirían formando parte de la nación porque sintieran más simpatías; probablemente sería España; pero nadie los violentará imponiéndoles una nacionalidad forzada, si quieren como ahora, vivir divididos» (Garrido, 1860: 332). 
Sin embargo, como se ha señalado ya, nunca se reconoció, como lo hizo la Constitución norteamericana de 1787, la existencia de un pueblo realmente plural, ni tampoco un reparto de competencias entre las distintas entidades soberanas en pie de igualdad. Los proyectos federales más importantes, aquellos que se elaboraron a partir de 1868, no precisaron con exactitud las competencias que corresponderían a cada entidad ni la manera en que se efectuaría el reparto de las mismas, y mantuvieron un modelo jerárquico en el que las entidades de menor tamaño quedaban sometidas al control de los organismos superiores. En el proyecto de Salmerón y Chao, de 1872, el Estado nacional era "el órgano superior del derecho", al que le incumbía «establecer los principios y reglas cardinales que han de presidir la constitución y funciones de todos los poderes en los Estados particulares, y fijar los principios fundamentales de justicia y sanción penal, bajo los cuales podrán estos legislar libremente». El municipio y el cantón serían «soberanos en su esfera interior de acción, sin más límite que los derechos de la personalidad humana y los principios constitucionales del Estado o Estados superiores». Ahora bien, en los cantones habría un delegado del poder ejecutivo de la nación que velaría por «la inviolabilidad de los derechos constitucionales». Eso sí, no podría intervenir de ningún modo en el gobierno y administración de los mismos. También habría un delegado del Tribunal Supremo que podría interponer recursos de casación contra las sentencias de tribunales inferiores opuestos «a los preceptos constitucionales o a la legislación general de la nación» (Salmerón y Chao, $1873: 7$ y 12 ).

El proyecto realizado un año más tarde por Cala y Díaz Quintero, por su parte, establecía que la Constitución y las leyes «que en su consecuencia dicten las cortes» eran "las leyes supremas de la nación», y que los cantones estaban «obligados a conformarse» con ellas. Los cantones debían proporcionar al Estado federal el contingente que les correspondiera en milicia cuando lo exigieran las Cortes de la federación, y contribuir en proporción de su riqueza a los gastos del gobierno federal. Ningún cantón podría ajustar "con otro pactos de carácter puramente político», aunque sí podrían celebrar "convenios [...] sobre objetos de legislación, administración o justicia». Solo al Congreso federal se le reconocía la facultad explícita de «dictar las leyes», y mientras que las funciones de este último estaban bien detalladas (mantener la paz interior, declarar la guerra, unificar pesos y medidas, etc.), no ocurría lo mismo con las funciones de los cantones. Sí se afirmaba que cada organismo conservaría «toda la plenitud de su soberanía no delegada expresamente en la Constitución nacional», lo cual no resultaba muy preciso, y tendría «libertad absoluta de formar su constitución regional», pero cada una de estas constituciones estaría sujeta «al juicio del Senado federal» (Díaz Quintero et al., 1873: 9, 22, 24, 31). 
El proyecto de Constitución de 1873, redactada principalmente por Castelar, estipulaba que los Estados tendrían la facultad de darse constituciones políticas, pero estas deberían estar sujetas al juicio y sanción de las Cortes federales y no podrían contradecir en ningún caso a la Constitución de la Federación. La atribución de competencias se efectuaba de arriba abajo: los Estados podrían regir su política propia, su industria, su hacienda, sus obras públicas, sus caminos regionales, su beneficencia, su instrucción y todos los asuntos civiles y sociales que no hubieran sido remitidos al Poder federal por la Constitución federal. Además, no podrían legislar «ni contra los derechos individuales, ni contra la forma democrática republicana, ni contra la unidad y la integridad de la Patria, ni contra la Constitución federal $»^{18}$.

Por otro lado, tras la formación de los Estados Unidos Ibéricos debía venir la de los Estados Unidos de Europa, un objetivo que, definido de distintas maneras, y con los precedentes de Saint Pierre, Rousseau, Kant, habían defendido los sansimonianos en las páginas de Le Globe, Buchez desde L’Européen, Lamennais en L'Avenir y posteriormente Considérant, Leroux, Mazzini, Ruge, Victor Hugo, Enfantin... Por lo general se soñaba con una confederación europea basada en un nuevo derecho de gentes internacional que aseguraría la paz continental a través del arbitraje de los conflictos por parte de un tribunal especial. Este tipo de ideas se defendieron en los numerosos Congresos por la Paz y la Unidad de Europa que se celebraron en Londres (1843 y 1851), Bruselas (1848), París (1849), Francfort (1850), Edimburgo (1853) o Ginebra (1861 y 1867 —a este último asistieron Victor Hugo, Quinet, Favre, Reclus, Stuart Mill y Castelar, y de él surgió el proyecto de Liga para la Paz y la Libertad que publicó el periódico Les Etats Unis d'Europe de 1868 a 1939-) (López Cordón, 1975: 39-41).

En España, El Eco del Comercio pidió en marzo de 1848 la formación de unos «Estados Unidos de Europa», porque Europa constituía «solo una gran nación, aunque dividida en varias provincias" (Basabe, 2010: 514). Unos años después, Orense señalaba que la marcha de las ideas en Europa tendía al establecimiento de un sistema lo más parecido posible al de los Estados Unidos, y Garrido pedía «la federación de todas las naciones de Europa, con el fin de facilitar el desarme de todos los ejércitos». Las contiendas se dirimirían en "parlamentos europeos». La federación permitiría "estrechar los lazos que unen a las razas del continente», permitir la libertad de comercio y la libre circulación de «cosas y personas» (Orense, 1853: 23; Garrido, 1860: 193).

18 Proyecto de Constitución Federal (1873). Disponible en: http://www.cervantesvirtual. com/servlet/SirveObras/78037393211469684865679/index.htm. 
Sin embargo, tampoco en este caso se pretendió imitar sin más el modelo norteamericano, sino que lo que se quería formar era realmente una Confederación de Estados. Para ello, era necesario que los distintos países europeos se organizaran primero federalmente. Garrido hablaba de 12 federaciones (suiza, francesa, ibérica, italiana, germánica, griega, polaca, holandesa, escandinava, británica, magiar-eslava, rusa) que constituirían «un cuerpo político cuyos lazos en nada coartarían la independencia de cada una» (1860: 356). Por lo demás, la confederación se organizaría con el objetivo de garantizar la libertad a todas las naciones integrantes, y de "generalizar en el mundo, entre los pueblos más bárbaros y atrasados, los principios de la libertad, de la justicia y de la tolerancia». Como consecuencia de estos principios, ninguna nación europea podría mantener ejércitos permanentes. Solo existiría un ejército confederal, integrado por un pequeño contingente proveniente de cada federación para defender las fronteras de «bárbaros o salvajes». La confederación funcionaría gracias a tres instituciones fundamentales: un congreso de diputados «nombrados cada uno por cada medio millón de habitantes», un senado compuesto de "tres o más miembros por cada estado», y un poder ejecutivo «compuesto de doce miembros, uno nombrado por cada estado».

El congreso discutiría las leyes, el senado las aprobaría o desaprobaría, y el poder ejecutivo las pondría en práctica. El senado debería reunirse una vez cada año, para constituirse en gran jurado y fallar sin apelación las quejas, que individuos, municipios o provincias tuvieran contra sus naciones respectivas, o unas naciones contra otras. Estas tres corporaciones no deberían disolverse nunca y podrían renovarse por terceras o quintas partes anualmente. Las atribuciones de las corporaciones de la federación europea se reducirían a dirigir las relaciones esteriores de Europa. A velar porque ningún gobierno atentase contra los derechos y libertades de su nación, ni de otra alguna fuese o no confederada. A lejislar cuanto se refiere a las relaciones internacionales, correos de mar y tierra, telégrafos, grandes líneas de caminos de hierro, obras de utilidad europea (Garrido, 1860: 358).

Todos los ciudadanos europeos serían electores y elegibles para las corporaciones europeas. Podrían votar aunque no residieran en su país de origen, bastando únicamente acreditar unos meses de residencia. La Constitución federal consignaría los derechos individuales, «que constituyen el dogma de la democracia», y ningún poder nacional ni provincial podría legislar sobre ellos ni coartarlos. La capital de esta gran Confederación no estaría en ninguna de las capitales existentes. "Como en los Estados Unidos» debería situarse en una ciudad neutral, como alguna de las hanseáticas o alguna de Suiza, "por más central y como honor concedido a la república que ha conservado su libre 
federación [...] durante trescientos años». La Confederación europea, concluía Garrido, aseguraría a todos los pueblos e individuos la libertad, representaría un ahorro de 4000 millones de reales anuales, e inauguraría una nueva era de paz, progreso y orden (Garrido, 1860: 360).

El proyecto de configurar unos Estados Unidos europeos nunca desapareció del horizonte republicano español, y el modelo para ello fue siempre el norteamericano. Castelar, de hecho, afirmaba en 1874 que «para llegar a los Estados Unidos de Europa» era "necesario imitar a los Estados Unidos de América». Este modelo jugó un papel fundamental en la cultura política democrático-republicana de las décadas centrales del siglo XIX pero fue leído e interpretado de manera particular; se tendió a enfatizar aquellas características que formaban parte sustancial del programa democrático; y su influencia no dio lugar a meras copias o imitaciones: en el caso de la «federación» española se trataría más bien de una descentralización política y administrativa, y en el de la europea, de una confederación. En cualquier caso, este y otros modelos extranjeros constituyeron referencias constantes en la publicística de los sectores demócratas y republicanos, y contribuyeron a dotar a la cultura política que configuraron de una importante dimensión transnacional: la mirada hacia el exterior no fue únicamente una manera de legitimar sus propuestas o difundir sus programas, sino que derivaba de una identidad de patriotas defensores de la emancipación de los pueblos que los vinculaba a activistas y movimientos democráticos foráneos, y los situaba en un movimiento general de lucha revolucionaria por la «libertad universal»(Peyrou, 2015).

\section{Bibliografía}

Angulo, A. (1865). Estudios sobre los Estados Unidos de América: la democracia y el self-government. Madrid: A. Durán.

Avecilla, J. O. (1843). Examen crítico-filosófico. Revolución de mayo de 1843. Madrid: Compañía Tipográfica.

Barcia, R. (1856). Catón político. Madrid: T. López Amor.

Basabe, N. (2010). Del Imperio a la Federación. La idea de Europa en Francia, 1800-1848. [Tesis doctoral inédita] Universidad Complutense de Madrid.

Borrego, A. (1885). Causas de la razón de ser del republicanismo en España. Madrid: sn.

Burdiel, I. (2004). Isabel II. No se puede reinar inocentemente. Madrid: Espasa.

Cámara, S. (1848). Espíritu moderno, o sea, carácter del movimiento contemporáneo. Madrid: Manuel Alvarez.

Capellán, G. (2011). La república norte-americana como modelo político para el krausismo español. Bulletin d'Histoire Contemporaine de l'Espagne, 46, 43-71.

Castelar, E. (1856). Prólogo. En F. Garrido, La República democrática, federal, universal. Madrid: La Asociación.

— (1874). Historia del movimiento republicano en Europa. Madrid: Manuel Rodríguez, t. I. 
Castro, D. (1987). Jacobinos y populistas. El republicanismo español a mediados del siglo XIx. En J. Álvarez Junco (ed.). Populismo, caudillaje y discurso demagógico (pp. 181-218). Madrid: CIS.

- (1990). La Revolución Francesa y el republicanismo español del siglo xix. En L. Busquets (ed.). Cultura hispánica y revolución francesa (pp. 147-159). Roma, Bulzoni.

- (1994). Orígenes y primeras etapas del republicanismo en España. En N. Townson (ed.). El republicanismo en España (1830-1977) (pp. 35-58). Madrid: Alianza.

Chopin, T. (2002). La république "une et divisible». Les fondements de la Fédération Américaine. Paris: Plon.

De Diego, J. (2008). Imaginar la República. La cultura política del republicanismo español, 18761908. Madrid: CEPC.

Díaz Quintero, F., Cala, R. y Benot, E. (1873). Proyecto de Constitución democrática federal de la República española. Madrid: s.n.

Duarte, À. (2004). Història del republicanisme a Catalunya. Vic: Eumo.

Elorza, A. (1997). El tema de Francia en el primer republicanismo español. En J. R. Aymes y J. Fernández Sebastián (eds.). L'Image de la France en Espagne (1808-1850) (pp. 107126). Bilbao: UPV.

Fleiner-Gerster, T. (1993). El federalismo en Europa. Barcelona: Hacer.

García Rovira, A. M. (1998). Radicalismo liberal, republicanismo y revolución (1835-1837). Ayer, 29, 63-90.

García Ruiz, E. (1861). La democracia, el socialismo y el comunismo según la filosofía y la historia. Madrid: C. González.

Garrido, F. (1860). La regeneración de España. Barcelona: Salvador Manero.

- (1868). Historia del reinado del último Borbón de España. Barcelona: Salvador Manero, t. III.

Gil Novales, A. (1996). Del liberalismo al republicanismo. En J. A. Piqueras y M. Chust (eds.). Republicanos y repúblicas en España (pp. 81-97). Madrid: Siglo XXI.

López Cordón, M. V. (1975). El pensamiento politico internacional del federalismo español. Barcelona: Planeta.

Marcuello, J. I. (1986). La práctica parlamentaria en el reinado de Isabel II. Madrid: Congreso de los Diputados.

Markoff, J. (1999). Olas de democracia. Madrid: Tecnos.

Méndez Vigo, P. (1835). España y América en progreso. Paris: Fournier.

Orense, J. M. (1851). Demostración de que las reformas propuestas por Orense están ya ensayadas. Bayona: Lespes.

— (1853). Histoire du parti libéral en Espagne. Bruselas: J. H. Briard.

- (1862). La democracia tal cual es. Madrid: J. A. García.

— (1863). Treinta años de gobierno representativo en España. Madrid: J. A. García.

— (1870). Derecho público republicano-democrático-federal. Madrid: J. Fernández.

Orobon, M. A. (2005). Marianne y España: la identidad nacional en la Primera República española. Historia y Política, 13, 79-98.

Pascual Sastre, M. I. (2002). La Italia del Risorgimento y la España del Sexenio democrático. Madrid: CSIC.

Peyrou, F. (2008a). Tribunos del pueblo. Madrid: CEPC. 
- (2008b). La formación del Partido Demócrata Español, ¿̨crónica de un conflicto anunciado? Historia Contemporánea, 37 (2), 343-372.

- (2009). Harmonia en la discordia. Reflexions al voltant de la cultura política democrático-republicana a Espanya, 1840-1868. Recerques, 58-59, 31-57.

- (2010). Los orígenes del federalismo en España: del liberalismo al republicanismo, 18081868. Espacio, Tiempo y Forma, 22, 257-278.

- (2015). The role of Spain and the Spanish in the Creation of Europe's Transnational Democratic Political Culture, 1840-1870. Social History, 40 (4), 497-517. Disponible en: https://doi.org/10.1080/03071022.2015.1076126.

Pi y Margall, F. (1998). A la República de los Estados Unidos de América (1896). Barcelona: Biblioteca de Catalunya.

Sagra, Ramón de la (1836). Cinco meses en los Estados Unidos de la América del Norte. Paris: P. Renouard.

Salmerón, N. y Chao, E. (1873). Proyecto de bases de la Constitución republicano federal de España. Madrid: Labajos.

Tresserra, C. (1870). Catecismo de la Federación republicano-democrática. Madrid: C. Moliner. 